The results arrived at are as follows :

1. That strychnia has an action on the heart, lessening its irritability, and that this action is probably direct.

2. That the mode of death by strychnia is not uniform; it may take place by a general impression on the nervous system -by asphyxia, and possibly by syncope, or syncope conjoined with asphyxia.

The conclusions drawn require to beconfirmed, the conditions under which the various phenomena are manifested to be exactly ascertained, and a general theory of the mode of action of strychnia to be established, explaining the whole.

June, 1856.

ON

\section{SOME CASES OF HERNIA TREATED AT ST. THOMAS'S HOSPITAL.}

WITH REMARKS.

By WALTER TYRRELL, Esq., M.R.C.S.,

IATE HOUSE-SURGJON TO THE HOSPITAL; SURGEON TO TER NATIONAL TRUSS SOCIEYY, ETC. ETC.

I PRopose to lay before the profession a series of cases of hernia, which came under my notice during my term of office at St. Thomas's Hospital. Some are interesting, as presenting peculiarities in their nature; others as illustrating varieties of treatment; and all, I am sure, if merely regarded as plain statements of facts, will not be deemed unworthy of record. They will be classed according to dates, and, when finished, a summary of the nature, treatment, and result, will be given. One point especially worthy of note in these cases is the extremely successful result of the application of ice to strangulated herniæ; as the cases will show, it has frequently been the means of procuring reduction of the tumour after other means had failed.

The first case is that of $R . B$ - , aged thirty-nine, a papermaker, who was admitted into Henry's ward, under the care of Mr. F. Le Gros Clark, Oct. 10th, 1854, suffering from strangulated scrotal hernia of fifty. eight hours' duration. The patient is an unhealthy-looking man, of phlegmatic temperament. He states that he has had a double scrotal hernia for fifteen years; he has worn a truss constantly during the day, but has had each rupture down once or twice, but never so as to cause him much inconvenience. On October 8th, about ten A.M., soon after he had gone to bed, and while asleep, (for he works during the night, ) his right rupture descended; it caused him considerable pain, and woke him. He found it larger than usual, and not to be returned in the ordinary manner. A sensation of sickness also came on, but he did not vomit unti later in the same day. He could not rest, as the pain and sickness continued, and at night he found himself quite unable to go to work. His symptoms continued unabated all night, with the addition of violent abdominal pains of a dragging nature. Towards evening he called in a medical man, who advised his immediate removal to the hospital. This, however, could not be done until the next morning. His bowels had not been opened for sixty hours. The patient reached the hospital at about eight A.M. on the third morning after the descent of the hernia. On admission, the tumour was tense and very tender; he had also much pain over the umbilicus. Mr. Clark had him removed to bed, and pounded ice applied in a bladder to the tumour; an enema, containing castor oil, was also given him. At three P.M. Mr. Clark again saw him, in company with Mr. South, and, finding that the ice had produced no effect, it was determined to operate at once. Mr. Clark performed the operation by making a small incision over the neck of the tumour, as he expected to find the constriction at the external ring. In this diagnosis he was correct. The sac was opened, and contained a large quantity of intestine, very much congested, but not presenting any signs of gangrene. After the operation the patient progressed favourably, with the ex ception of being troubled with obstinate tympanitis, which lasted some days, and resisted all means of relief. His bowels were not freely opened until three days after the operation; but from that time this painful symptom declined. About a week after the operation he was quite free from pain, his tongue clean, and the wound healing rapidly.

October 21st. - Wound nearly healed; bowels open regularly;

sleeps well; appetite good. A week after this, he was measured for a truss; and on November 7th, twenty-eight days after the operation, he was discharged cured.

With this case, I would compare one which was admitted on the following day, and in many respects presents a striking resemblance to the one just described. It is that of James $\mathrm{B}_{-}$, a fine, healthy-looking young man, aged twenty-one, who gives the following account of his disease :- He has always had some small amount of swelling in the right side of his scrotum, and this was at times increased by a protrusion which ran up into his groin. This, however, always returned without causing him any inconvenience. He had no suspicion of rupture, and had never worn a truss. His occupation was laboriousthat of a railway porter. Two nights before, he had gone to bed about ten o'clock, and had been there about an hour, when he was awoke by severe pain in his belly. On examination, he found the swelling in his scrotum much increased in size, and very painful to the touch. The pain continued through the night; he could not rest; and in the morning he sent for a medical man, giving as his symptoms pain in the belly, sickness, \&c. Not mentioning the tumour, two pills and a purgative draught were ordered, and, as might be expected, only with the effect of increasing the sickness. He had no motion. In the evening, the medical man again called, and his attention was now drawn to the tumour. He made an attempt to return it, but without effect, and advised his removal to the hospital. The patient continued in agony all night, with increased sickness, and violent dragging pain at the umbilicus. He reached the hospital on the morning of the 11 th of October, and was admitted into Henry's ward, under the care of Mr. F. Le Gros Clark. Immediately on his admission, pounded ice in a bladder was placed on the tumour, and kept on for about half an hour. On its removal, taxis was again applied, but with no better success, as the extreme tenderness of the tumour prevented any continued attempts. Soon after this, Mr. Clark saw him, and proposed immediate operation. It was accordingly performed. On opening the sac, a large quantity of fluid escaped, cliffering from that usually found in hernial sacs, being thicker, and more viscid. On further opening the sac, the testicle was found lying at the lower part, thus confirming an opinion that Mr. Clark had expressed previous to the operation - that the hernia was of the congenital form, and accompanied with hydrocele. A knuckle of intestine, about the size of a pigeon's egg, and of a deep port-wine colour, was then returned, and the patient replaced in bed. From that time, he had not one bad symptom, his bowels were freely opened the same night, and by November 7 th he was discharged cured.

These cases present many points of similarity. In both, the symptoms at the time of operation were urgent; and in both the intestine, when exposed, was found to be deeply congested; and both, more particular the latter, may be looked upon as good instances of what has been termed " inflammatory strangulation." But the most remarkable point is, that in both cases the protrusion and strangulation took place while the patient was in the horizontal position asleep, and, as far as they could say, not making any unusual effort. This would certainly show the necessity of constantly wearing the truss, not merely with the view to obtaining a permanent cure if possible, but even for purposes of saiety.

St. Helen's-place, 1556 .

ON

\section{PREGNANCY COMPLICATED WITH TUMOUR IN THE PELVIS.}

By THOS. R. MITCHELL, M.D., F.R.C.S.I.

Some of the most puzzling cases in practice, requiring all the tact and experience of the practitioner, arise from tumours in the abdomen; and as I think the particulars of the following case are both interesting and instructive, I shall, without further preface, proceed to detail them.

In February, 1855, I was consulted by Mrs. B-, aged forty-three, the mother of three children; she had also aborted once, and, I was informed, was suffering from a tumour in the abdomen of more than twelve months' duration. She had seen several practitioners, and undergone a variety of treatment, prior to my seeing her. I ascertained that she had not menstruated for four months, and complained of great pain in the abdomen, the pressure of her clothes being most distressing, 
accompanied with bearing-down sensation, loss of appetite, and constant nausea and vomiting; the bowels were very constipated; tongue foul; pulse 95 , small and weak. She told me that five years ago she had a very bad labour, that instruments were used, and that from that period she had always menstruated regularly until within the last four months, having lived quite separate from her husband all that time, being informed that another pregnancy would be likely to prove fatal. On examining the abdomen, which was very Jarge, tympanitic, and tender, I succeeded, after a good deal of manipulation, in detecting a tumour of considerable size in the right hypogastrium. The examination was, however, most unsatisfactory, in consequence of the distress occasioned and the tympanitic condition of the belly. A vaginal examination did not assist the least in the diagnosis, the parts being normal, and in situ, with the exception of a slight anteversion of the uterus. Examination per rectum elicited the presence of a considerable fullness pressing upon the posterior walls of the rectum, and obscurely fluctuating. A stethoscopic examination elicited nothing. The breasts were very soft and flaccid, no areola perceptible around the nipples, nor any of the glandula in the neighbourhood enlarged.

Not feeling satisfied as to the nature of the case, I ordered a brisk cathartic of turpentine and castor oil, which dispelled a quantity of flatus, and allowed a much better examination on the following day. The tumour seemed to be attached to the posterior part of the uterus, but so indefined as to render any opinion as to its nature of little use. I accordingly directed my attention to allay the more troublesome symptoms, particularly the nausea and vomiting. Prussic acid was given internally, and the bowels regulated by the administration of enemata daily, together with light, nutritious food in small quantities. She seemed at first to improve a little under the treatment, but the sickness was most distressing, and the prostration so great as to prevent her leaving her bed. Having an idea that the tumour might be owing to a collection of fæces in the colon, a circumstance which had previously occurred to myself in practice, I introduced an O'Bierne's tube. The instrument passed up, without any difficulty, its whole length, but, with the exception of a slight escape of flatus, no good resulted, except of a negative character.

Ten days later, I met another practitioner in consultation, and the various examinations, abdominal, vaginal, rectal, and stethoscopic, were repeated, but withont assisting the diagnosis in the least. It was evident that so much constitutional disturbance must have a cause, and it was determined to watch the case, and meet symptoms as they arose. All idea of pregnancy was stoutly and indignantly denied.

Towards the latter end of Mareh, the lady complained of pain in the right breast, which led to an examination. I found it fuller, and with a slight moisture around the nipple; the skin was also darkcr. On making a careful stethoscopic examination, I detected a faint bruit, and informed my patient's sister of my suspicion. Early in April, I heard the foetal heart distinctly, which set the matter at rest, although the lady assured me she was unconscious of the fact.

Everything was allowed to remain as a matter of course; and although confined almost entirely to bed, as the enormous size of the abdomen precluded motion, and produced great sickness, still by attention to diet, and regulation of the bowels, she suffered less than might have been expected. Labour came on on the 18th of July; the first stage was very tedious and distressing, the prostration being great. After twenty four hours' labour, I felt, what at first seemed to be the mem brane protruding, but which, on a careful examination, I found to be the whole posterior wall of the vagina, which was pushed down, and as large as a child's head. At this time the os nteri was dilated to the size of half-a-crown, the head presenting, and the membranes unruptured. The pains were now so distressing, and her shrieks so violent, that $X$ put her under the influence of chloroform, its administration being kept up during the whole of the after part of labour. At this stage, a consultation on the case was held with another practitioner, when, as there appeared sufficient room for the exit of the child, and as no urgent symptom was present, it was determined to leave Nature to herself. The catheter was used, and an enema given. At six o'clock P. Mr., after thirty-two hours' labour, the os uteri was fully dilated, pains brisk and frequent, head above the brim of pelvis; I ruptured the membranes, the pains became frequent, but there was no advance of the head. The longcontinued pain was now beginning to tell upon her, the pulse rose to 110 , stomach very irritable, and considerable tenderness over the abdomen. The uterine action was brisk, frequent, and powerful; but it was evident that Nature could not effect the delivery, the obstruction being too great, the posterior part of the pelvis being completely filled with a firm solid body, apparently passing behind the rectum, and protruding that viscus before it, so as to occupy nearly the entire of the pelvic cavity. Having, therefore, waited as long as I thought safe, I determined to deliver her, and tried first with the long forceps. I could not, however, succeed in locking them, and therefore did not deem it prudent to persevere, but perforated the child's head; and, after some delay, and no slight pulling, delivered her. The placenta was extracted from the vagina in half an hour after the delivery. The uterus contracted pretty well; but as the pulse continued above 100 , I remained some time with her for fear of flooding. which was not however violent, and quickly succumbed to a dose of ergot, and the compress and bandage.

Her recovery was very slow and tedious. On the third day symptoms of peritonitis showed themselves, but having given her small doses of calomel and opium immediately after the delivery, they soon subsided; she was not, however, able to leave her bed for two months, and could not walk across the room even then. By degrees, however, she gained strength, and is now able to walk two or three miles. The prolapse of the rectum was most distressing for some time, but as the uterus ascended into the pelvis it disappeared, clearly proving that the tumour was attached to the uterus. Numerous careful examinations after the delivery failed in discovering the exact nature or condition of the tumour, being evidently at the back part of the uterus and close to the spine. The lady, at the commencement of the present year, enjoyed pretty good health, and suffered no inconvenience except at each menstrual period, when she experienced a good deal of pain.

There are, I think, in this case several points of great practical importance, fully showing how careful we ought to be in forming our diagnosis, and how necessary that we should not be induced to place implicit reliance on the statements of patients or their friends. It is, indeed, a great wonder that the uterus did not expel its contents, when we consider the vast amount of provocation it received, and the powerful means that were employed. I have no doubt that the tumour had existed for years, and that it was the cause of difficulty in her former labour, and induced her medical attendant to warn her against any future pregnancy.

Liverpool, 1856

oN

\section{NEGLECTED PURULENT OTORRHEA AND ITS RESULTS.}

\section{By THOMAS WESTROPP, EsQ., M.R.C.S.,} Bristol.

As long as obstinate popular prejudice and stubborn medical indifference, if not ignorance, coexist on the subject of diseases of the ear generally, so long will it be the duty of those who are conversant with the subject to protest frequently against errors so fatal in their tendencies, till at length the danger of neglected purulent discharges from the ear shall have become as familiar as " household words."

This is no new fact: $\epsilon$ very writer of repute on aural surgery has insisted on it; every modern well-written book on general surgery directs attention to it. Fatal cases are occasionally detailed in the medical journals, lectures of eminent men are published, all tending to establish the certain fact, and advocating the necessity of immediate scientific and patient attention being paid to ear affections, and especially to otorrhoea. Yet, after all this, althongh one would think a tyro in his profession ought to thoroughly understand it, an amount of carelessness, ignorance, prejudice, and utter neglect, is daily to be observed, both amongst patients, as well as amongst their medical advisers, with very few exceptions. I can scarcely account for it: all I know is, that it is a palpable fact-a fact which, I am sure, every aural surgeon in the kingdom will corroborate from his own experience. One reason may be, that it requires more than ordinary trouble, dexterity, and patience to properly investigate the details of an ear case; suitable apparatus and instruments are required which are not in 